\title{
REVIEW \\ Fruit Productivity of Vertically Trained Watermelon (Citrullus lanatus (Thunb.) Matsum. et Nakai) plants
}

\author{
Shin-ichi WATANABE* \\ Lowland Farming and Horticulture Research Division, NARO Kyushu Okinawa Agricultural Research \\ Center (Kurume, Fukuoka 839-8503, Japan)
}

\begin{abstract}
We examined the fruit productivity of vertically trained watermelon plants, focusing on leaf area, light reception, and field photosynthesis characteristics. We also examined the source-sink relationships of photosynthates during fruit development to characterize fruit productivity in vertical training. Furthermore, the fruit productivities of both the plant and unit land area were compared between vertical training systems and conventional, horizontal training systems. The fruit weight of both types of watermelon plants could be determined by the total leaf area, total solar radiation received, and photosynthetic production per plant. Regardless of the leaf position, most photosynthates of vertically trained watermelon plants during fruit development were distributed to the fruit, meaning the fruit weight could be determined by the above-mentioned factors. Photosynthates for roots were characteristically distributed from leaves on non-fruiting vines in plants with two vines and one fruit, and from limited lower leaves in plants with one vine and fruit respectively. Vertical training of watermelon plants increased the fruit yield per unit land area under higher planting density than horizontal training, with no loss of light-use efficiency.
\end{abstract}

Discipline: Horticulture

Additional key words: ${ }^{13} \mathrm{C}$-photosynthates, leaf area, light interception, photosynthesis, planting density

\section{Introduction}

The watermelon (Citrullus lanatus (Thunb.) Matsum. et Nakai) is a major, high-production fruit vegetable in Japan with yearly production following that of cucumbers and tomatoes ${ }^{1}$. It is also one of the major vegetables subject to protected cultivation in Japan. Although its protected cultivation area follows those of tomatoes, melons, spinach, strawberries and cucumbers, it is mainly cultivated in open fields. However, production is gradually declining ${ }^{1}$. One of the main reasons for this decline is the labor involved in managing conventional crops, whereby vines are trained horizontally on the ground surface. This practice means that growers must work in uncomfortable positions to train the vines, hand-pollinate the flowers and harvest the fruit. Recently, vertical training has emerged as an alternative due to the reduced crop management labor involved (Fig. 1). In vertical training, vines are trained upward on supports and fruit are suspended by strings and/or nets, so that growers can perform many tasks standing rather than crouching
(Figs. $2 \& 3$ ). To introduce a vertical watermelon training system more widely, the characteristics of fruit productivity and related advantages must be objectively clarified in comparison with conventional, horizontal training systems. Although it is surmised that fruit productivity differs considerably between the respective training systems due to the wide difference in the way the vines are arranged, there are

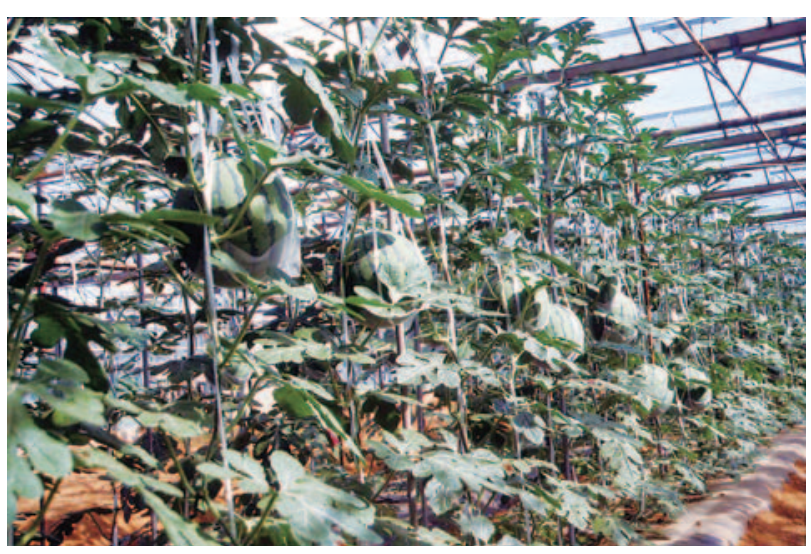

Fig. 1. Vertical training of watermelon plants 
few relevant reports in this area, not only for watermelon but also other fruit vegetables ${ }^{2,3,4}$. We examined the fruit productivity of vertically trained watermelon plants, focusing on leaf area, light reception, and field photosynthesis characteristics. We also examined the source-sink relationships of photosynthates during fruit development to characterize fruit productivity in vertical training. Subsequently, we compared the fruit productivity both per plant and per
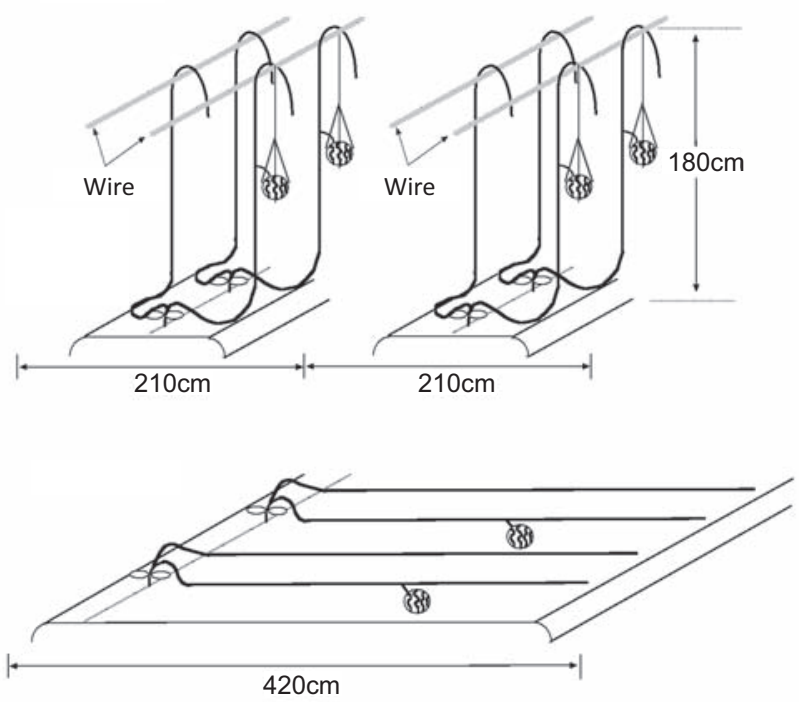

Fig. 2. Example of a vine arrangement in vertical (upper) and horizontal (lower) training systems

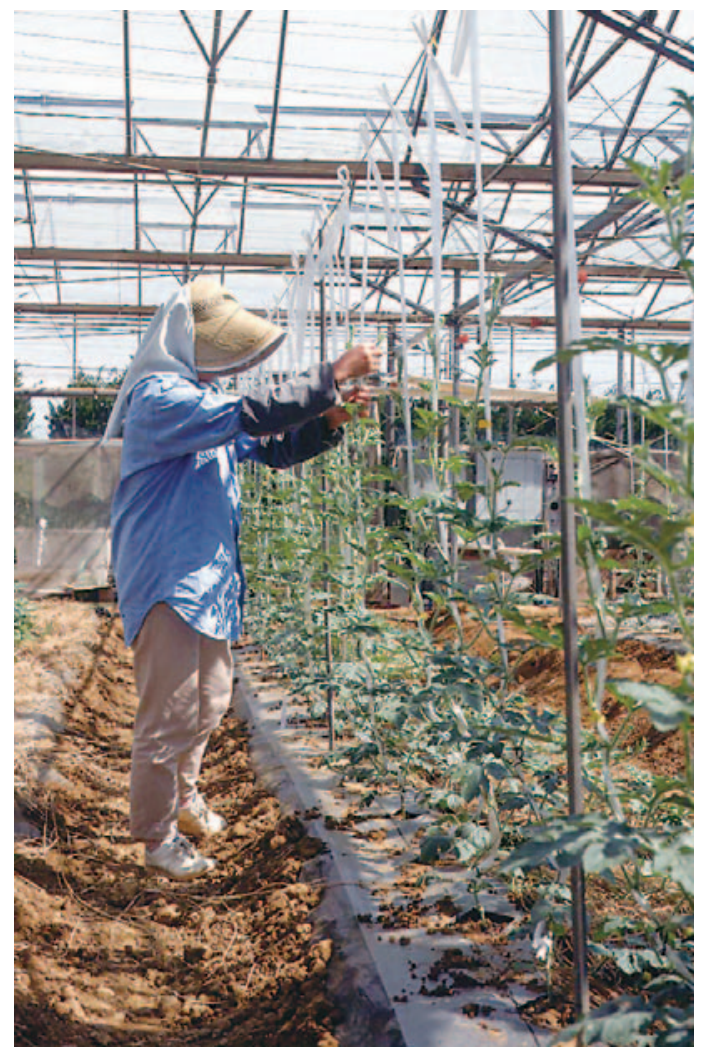

unit land area between vertical training systems and conventional, horizontal training systems.

\section{Factors influencing the fruit enlargement of vertically trained watermelon plants}

\section{Effects of the fruit set position on total leaf area per plant and fruit weight}

We examined the effect of the fruit set position on total leaf area per plant and final fruit weight in vertically trained plants $^{8,10}$. Two primary lateral vines were allowed to grow in each plant, and one fruit per plant was set at the 3 rd to 5 th, 8 th to 11 th, 14 th to 16 th or 18 th to 22 nd node. Each vine was pinched at the 22 nd node.

The fruit weight grew with increasing fruit set position (data not shown). Total leaf area per plant during the fruit development also rose with increasing fruit set position (Fig. 4). The fruit weight at harvest was closely related to the total leaf area per plant at 5, 20, and 40 days (harvest) after pollination (Fig. 5). We concluded that decreased photosynthetic production due to smaller leaf area and competitive growth between the fruit and vegetative organs during fruit development caused smaller fruit to develop when fruiting occurred at a lower node position.

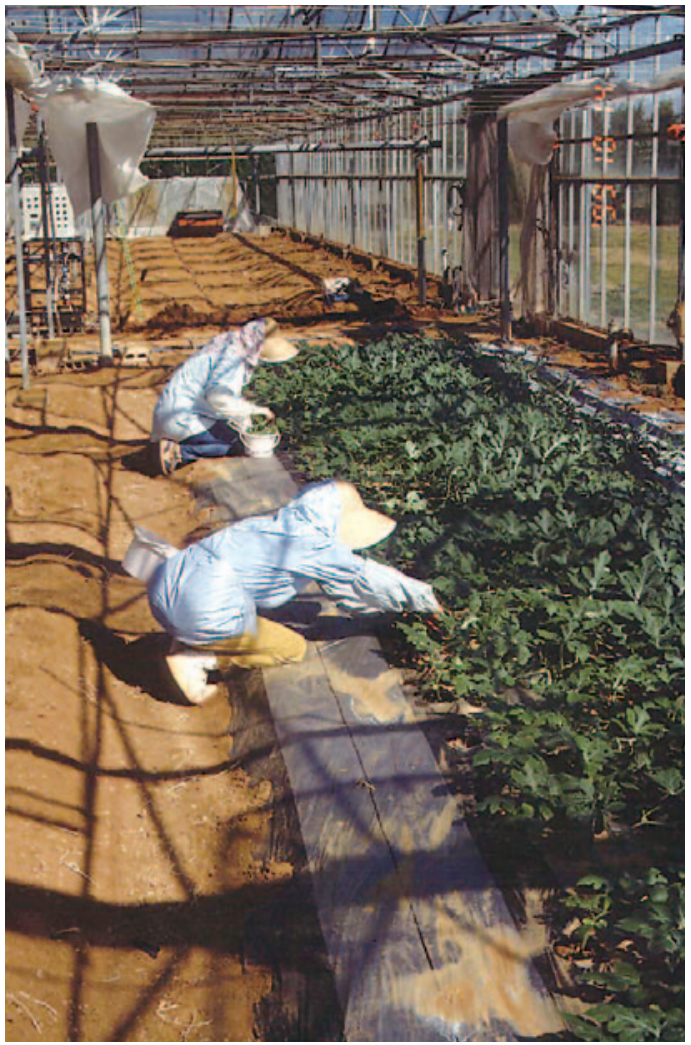

Fig. 3. Working postures in vertical (left) and horizontal (right) watermelon training systems 


\section{Relationships between total leaf area and fruit weight}

We investigated the effect of the pattern of vertical training on fruit weight in relation to the total leaf area per plant $^{7,10}$. In June- and November-harvest crops, one to three vines were allowed to grow and one fruit was set per plant.

During both growing seasons, fruit weight was closely related to total leaf area per plant, regardless of the training pattern (Fig. 6). However, the regression lines between fruit weight and total leaf area per plant differed between the growing seasons. Accordingly, further investigation on

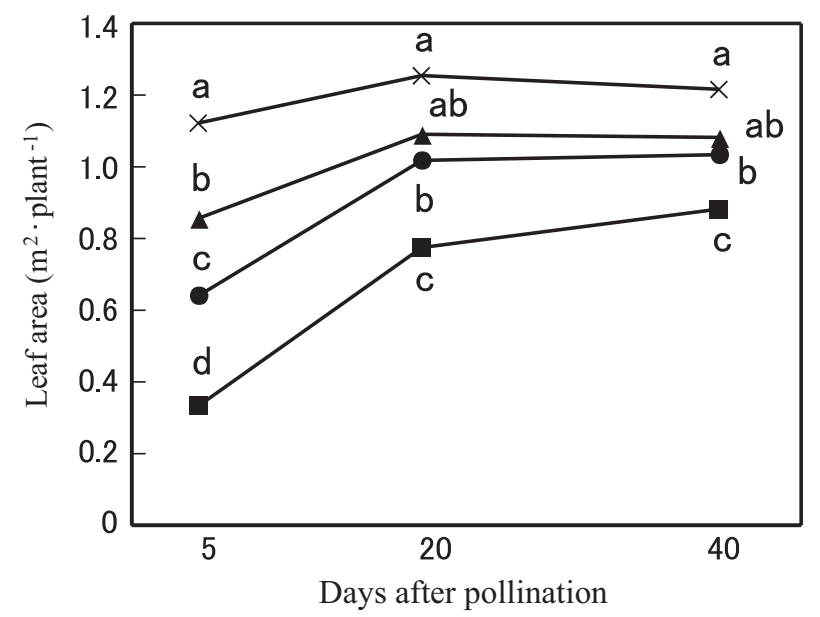

Fig. 4. Effect of fruit set position on the change in total leaf area per plant

cv. 'Shimaou max RE'. Different letters within the same days after pollination indicate significant differences exposed by the Tukey-Kramer test at $P<0.05$ [n=8 (5 and 20 days after pollination), $\mathrm{n}=12$ 13 (40 days after pollination)].

$\rightarrow-3$ rd - 5th node $\quad \rightarrow-8$ th - 11th node $\leftarrow$ 14th -16 th node $\quad * 18$ th -22 nd node light reception was needed to analyze the characteristics of fruit enlargement in vertical training.

\section{Effects of planting density on fruit weight, light- interception and photosynthetic production}

We investigated the effect of planting density on the fruit weight of vertically trained plants in terms of light reception among expanded leaves and photosynthetic production $^{9,10}$. Two primary lateral vines per plant were allowed to grow and one fruit was set. Solar radiation on individual leaves was measured during the fruit development with an integrated solarimeter film ${ }^{5}$ and the photosynthetic rates of these leaves were measured with a portable photosynthesis system. The total solar radiation received by the whole plant was estimated by totaling up the solar radiation received by individual leaves, as estimated by multiplying the solar radiation received by the solarimeter film on the leaf by the individual leaf area. Similarly, the photosynthetic production of the whole plant was estimated by totaling up the photosynthetic production of individual leaves, as estimated by multiplying the determined value of photosynthetic rate by the individual leaf area.

The solar radiation received and the photosynthetic rate of the individual leaves gradually fell with descending leaf position at all planting densities, while the decreasing rates of solar radiation received and the photosynthetic rate of the individual leaves tended to be greater at higher planting densities (data not shown). Fruit weight decreased significantly with increasing planting density (data not shown). Although fruit weight was closely related to the total leaf area per plant at each planting density, the regression lines between the fruit weight and total leaf area per plant differed among planting densities (Fig. 7). Fruit weight was obviously proportional to both the total solar radiation received

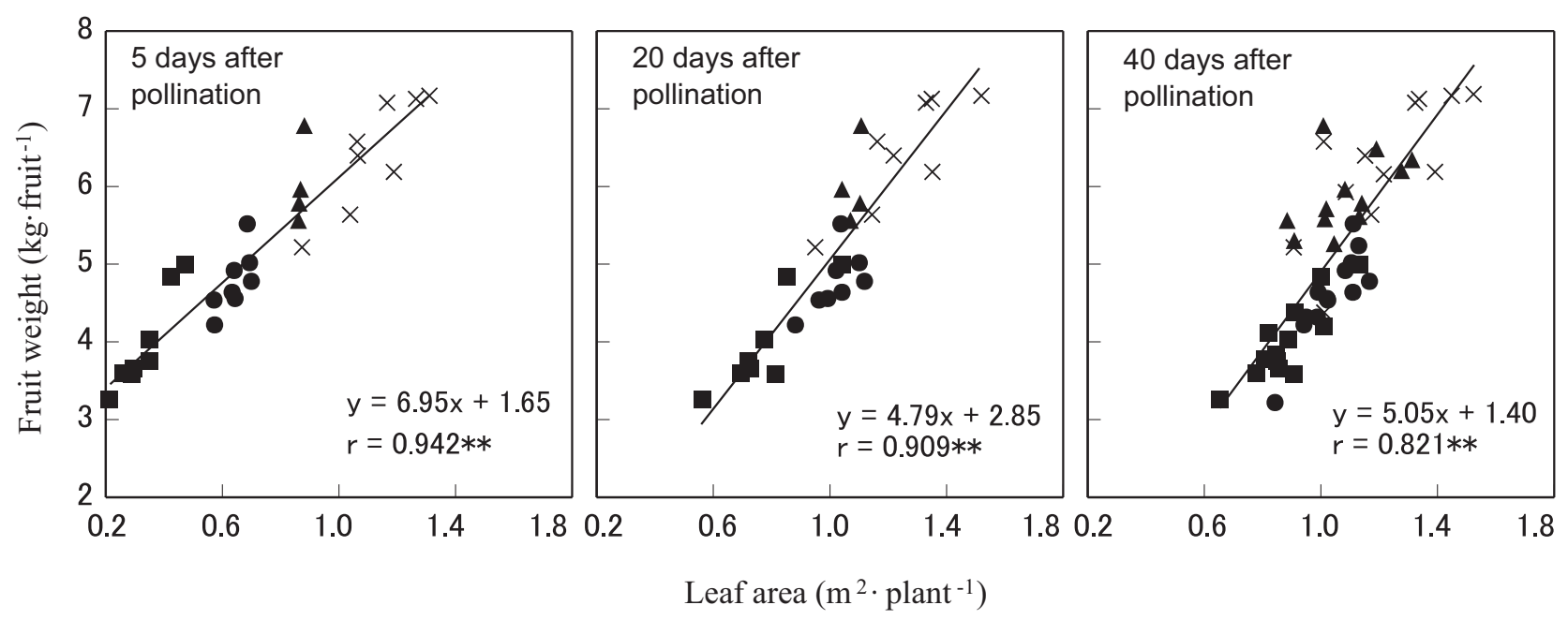

Fig. 5. Relationships between total leaf area per plant at 5, 20, and 40 days (at harvest) after pollination and final fruit weight at harvest

cv. 'Shimaou max RE'. ** indicates significance at $P<0.01$.

3rd - 5th node 8th-11th node $\Delta$ 14th - 16th node $\times 18$ th -22nd node 


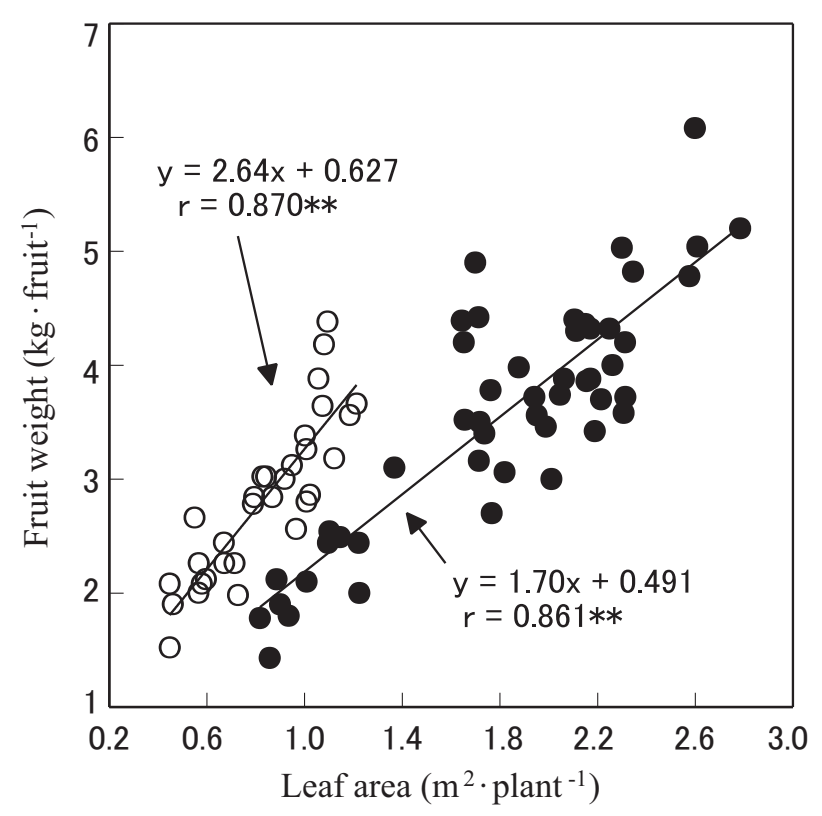

Fig. 6. Relationships between total leaf area per plant and fruit weight for vertically trained watermelon plants in the June-harvest crop ( $($ ) and November-harvest crop (•)

cv.'Wase Tenryu'. ${ }^{* *}$ indicates significance at $P<0.01$.

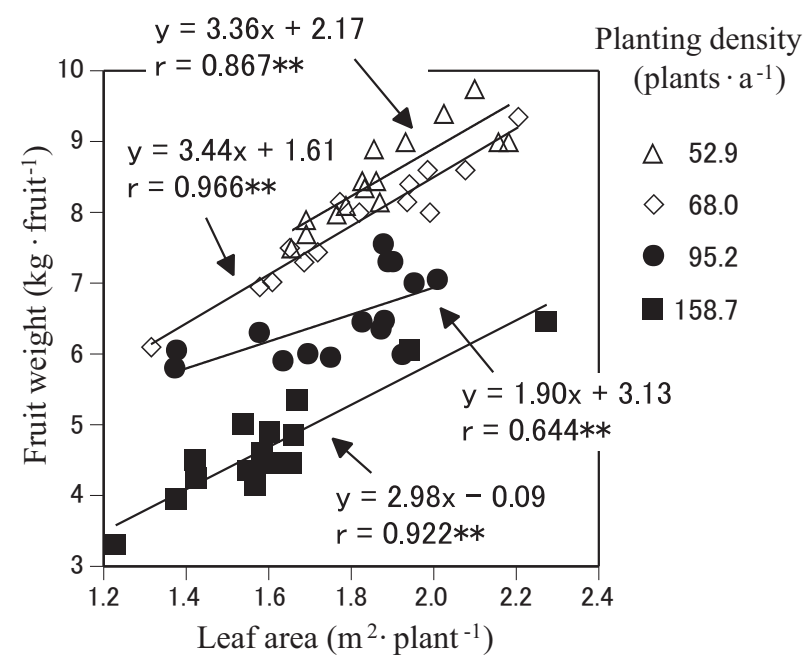

Fig. 7. Effect of planting density on the relationships between total leaf area per plant and fruit weight in vertically trained watermelon plants

cv. 'Shimaou max RE'. ** indicates significance at $P<0.01$.

and the photosynthetic production per plant (Fig. 8).

The above results indicate that the total leaf area per plant could determine differences in fruit weight in vertically trained plants within a certain range of planting densities or training patterns during the same growing season. However, over a wider range of planting densities or training patterns, or during a different growing season, the total
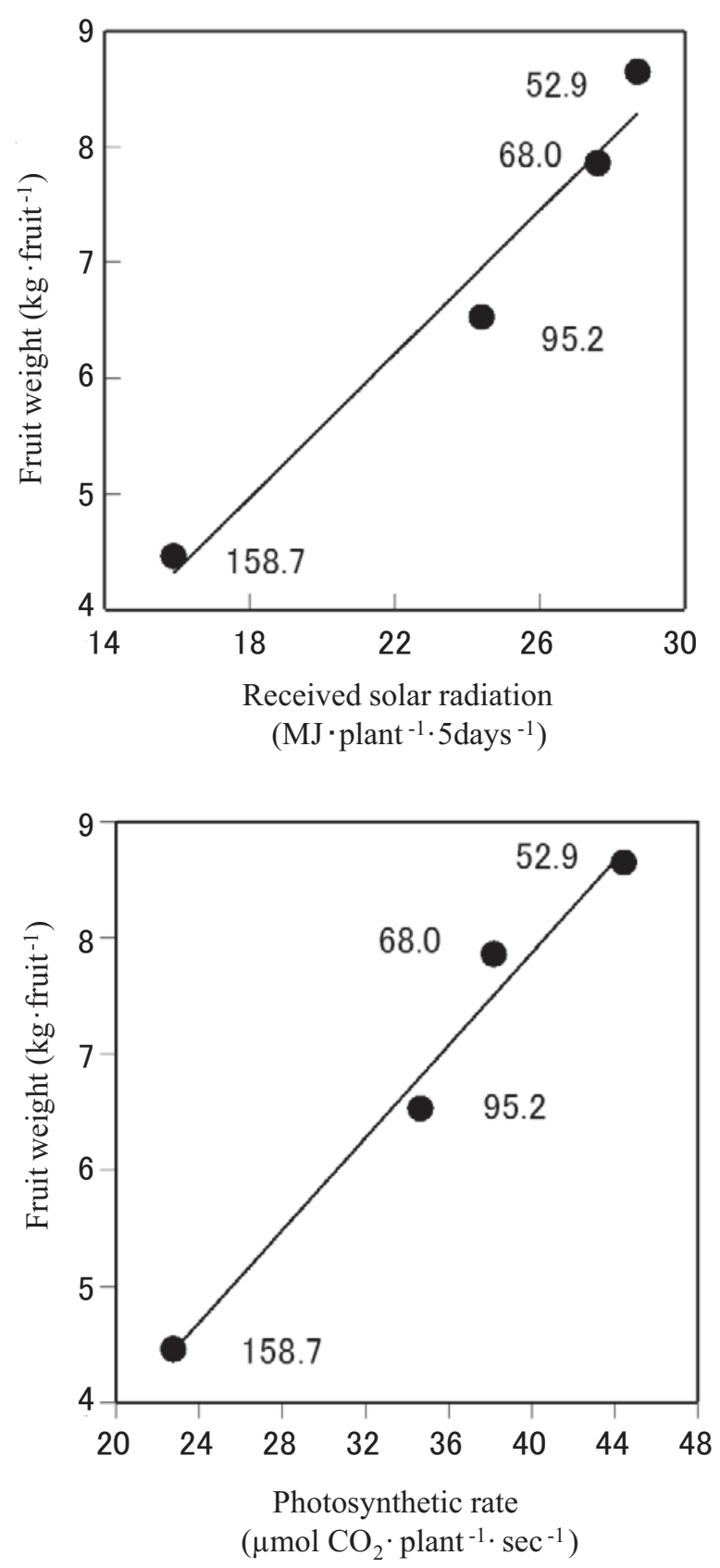

Fig. 8. Relationships between solar radiation received (upper) or estimated $\mathrm{CO}_{2}$ fixation (lower) by the whole plant and fruit weight during fruit development at different planting densities

cv. 'Shimaou max RE'. Numerals in the graph indicate the planting density (plant $\left.\mathrm{a}^{-1}\right)$.

solar radiation received and photosynthetic production per plant are likely to be more appropriate factors than the total leaf area per plant when investigating the characteristics of fruit enlargement.

\section{Distribution of ${ }^{13} \mathrm{C}$-photosynthates during fruit development in vertically trained watermelon plants}

We used the ${ }^{13} \mathrm{C}$-tracer method to investigate the trans- 
location and distribution of photosynthates during fruit development in vertically trained plants with one or two vines and one fruit ${ }^{10}$.

\section{Distribution of ${ }^{13} \mathrm{C}$-photosynthates during fruit development in plants with two vines and one fruit}

Plants with two primary lateral vines pinched at the 23th node and one fruit set at the 10th to 13th node on either vine were fed ${ }^{13} \mathrm{CO}_{2}$. ${ }^{13} \mathrm{CO}_{2}$ feeding treatments were performed three times, during early, middle and late fruit developing stages and on sunny days during the fruit developing period. ${ }^{13} \mathrm{CO}_{2}$ were fed to four different portions, upper leaves at nodes 18 to 20 and lower leaves at nodes 3 to 5 on a fruiting or non-fruiting one, changing the feeding portion according to the plant (Fig. 9). Once 48 hours had elapsed since the ${ }^{13} \mathrm{CO}_{2}$ feeding treatment, the plants were sampled by respective portions (Fig. 9) and their ${ }^{13} \mathrm{C}$ content was determined.

More than $89 \%$ of exported ${ }^{13} \mathrm{C}$ from ${ }^{13} \mathrm{C}$-fed leaves was distributed to the fruit, regardless of leaf position and fruit developing stage (Table 1), meaning most of the photosynthates in the whole plant were transported to the fruit

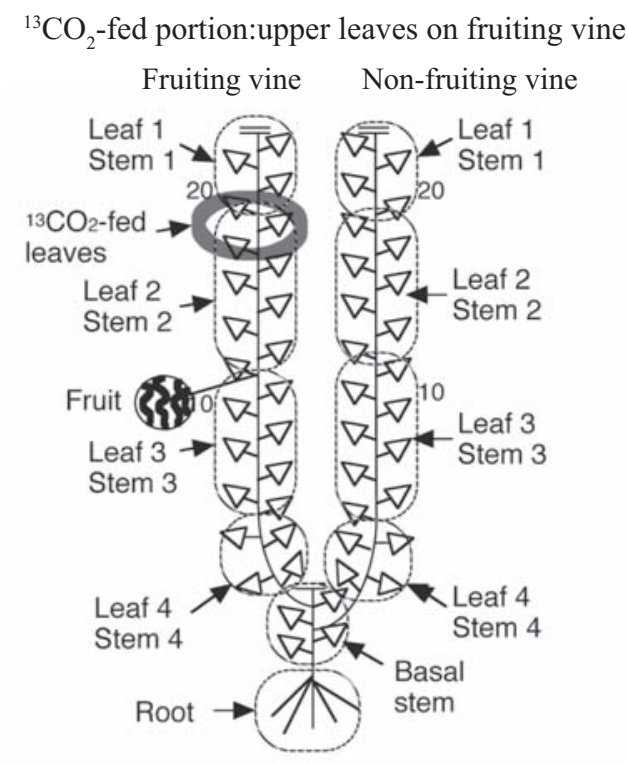

\section{${ }^{13} \mathrm{CO}_{2}$-fed portion:lower leaves on fruiting vine}

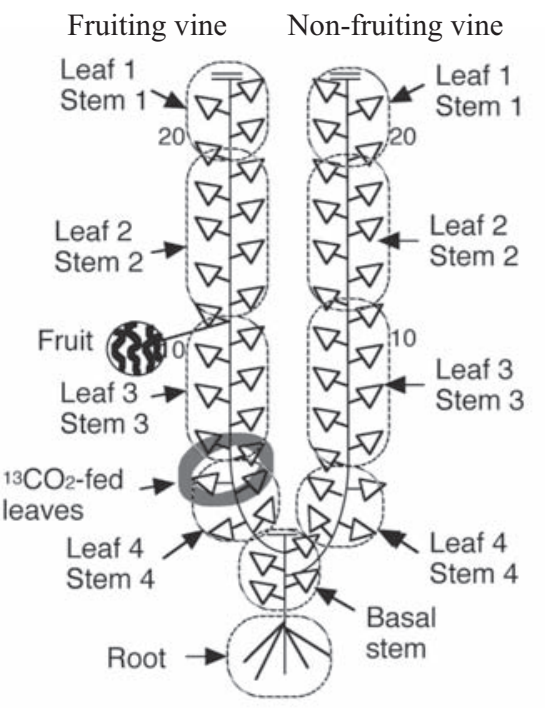

${ }^{13} \mathrm{CO}_{2}$-fed portion:upper leaves on non-fruiting vine

${ }^{13} \mathrm{CO}_{2}$-fed portion:lower leaves on non-fruiting vine

Fruiting vine Non-fruiting vine
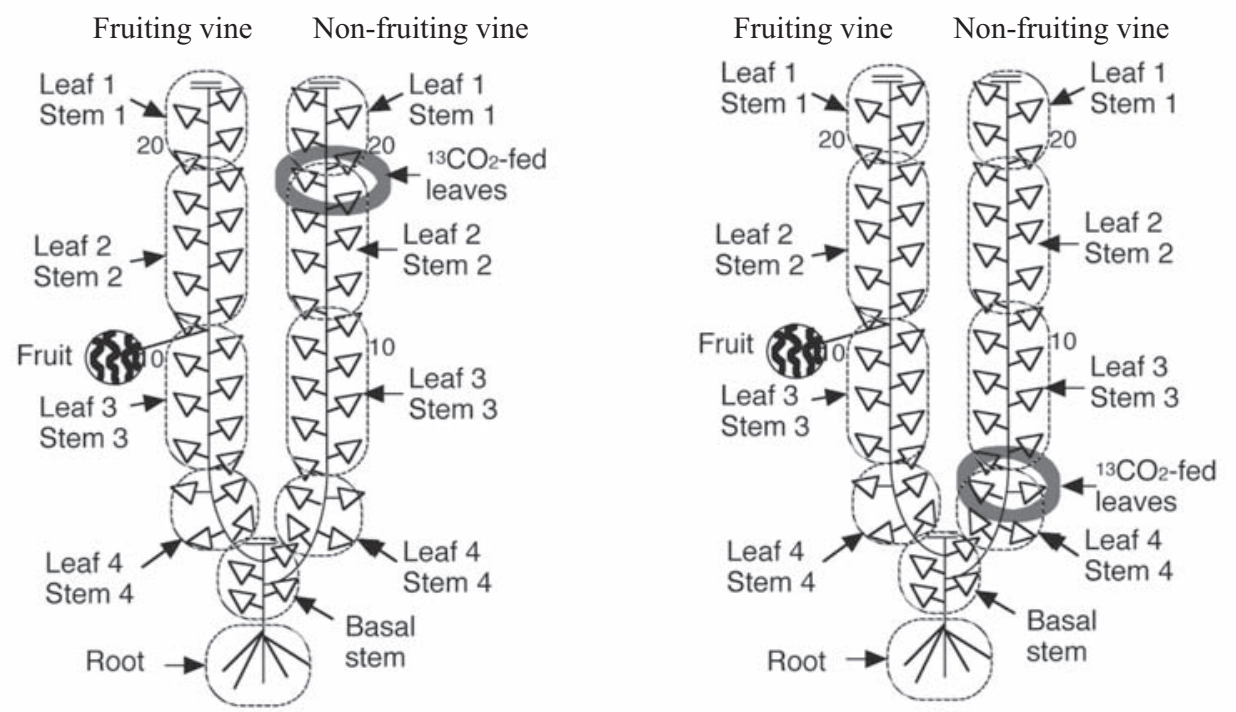

Fig. 9. Portions of ${ }^{13} \mathrm{CO}_{2}$ feeding and sampling sections for analysis in watermelon plants with two vines and one fruit

cv. 'Shimaou max RE'. $\bigcirc$ indicate the portions of ${ }^{13} \mathrm{CO}_{2}$ feeding. Sampling sections of leaves and stems were as follows, Leaf 1 and Stem 1 were leaves and stem from the 20th to 23rd nodes, Leaf 2 and Stem 2 were leaves and stem from the 13th to 19th nodes, Leaf 3 and Stem 3 were leaves and stem from the 5th to 12th nodes, and Leaf 4 and Stem 4 were leaves and stem under the 4 th node on the respective lateral vines, respectively. ${ }^{13} \mathrm{CO}_{2}$ feeding leaves were excluded from the sampling sections. 
Table 1. Distribution of ${ }^{13} \mathrm{C}$-photosynthates in vertically trained watermelon plants with two vines and one fruit during fruit development

\begin{tabular}{|c|c|c|c|c|c|c|c|c|c|c|c|c|c|c|}
\hline \multirow{4}{*}{\multicolumn{3}{|c|}{ Section }} & \multicolumn{12}{|c|}{ Portion of ${ }^{13} \mathrm{CO}_{2}$-fed leaves } \\
\hline & & & \multicolumn{6}{|c|}{ Fruiting vine } & \multicolumn{6}{|c|}{ Non-fruiting vine } \\
\hline & & & \multicolumn{3}{|c|}{ Upper leaves } & \multicolumn{3}{|c|}{ Lower leaves } & \multicolumn{3}{|c|}{ Upper leaves } & \multicolumn{3}{|c|}{ Lower leaves } \\
\hline & & & Early $^{\mathrm{z}}$ & Middle $^{\mathrm{z}}$ & Late $^{2}$ & Early & Middle & Late & Early & Middle & Late & Early & Middle & Late \\
\hline \multicolumn{15}{|c|}{ Fruiting vine } \\
\hline & Leaf & 1 & 1.3 & 0.0 & 0.0 & 0.0 & 0.0 & 0.0 & 0.1 & 0.0 & 0.0 & 0.0 & 0.0 & 0.1 \\
\hline & Stem & 1 & 3.0 & 0.1 & 0.2 & 0.0 & 0.0 & 0.1 & 0.0 & 0.1 & 0.1 & 0.0 & 0.0 & 0.1 \\
\hline & Leaf & 2 & 0.2 & 0.0 & 0.0 & 0.2 & 0.0 & 0.0 & 0.0 & 0.0 & 0.0 & 0.0 & 0.0 & 0.0 \\
\hline & Stem & 2 & 3.7 & 0.3 & 1.0 & 0.0 & 0.0 & 0.0 & 0.0 & 0.1 & 0.0 & 0.0 & 0.0 & 0.2 \\
\hline & Leaf & 3 & 0.1 & 0.0 & 0.0 & 0.0 & 0.0 & 0.0 & 0.0 & 0.0 & 0.0 & 0.2 & 0.0 & 0.0 \\
\hline & Stem & 3 & 0.4 & 0.0 & 0.1 & 1.4 & 0.7 & 2.6 & 0.6 & 0.2 & 0.8 & 1.4 & 0.1 & 1.8 \\
\hline & Leaf & 4 & 0.1 & 0.0 & 0.1 & 0.0 & 0.0 & 0.2 & 0.0 & 0.0 & 0.0 & 0.0 & 0.0 & 0.0 \\
\hline & Stem & 4 & 0.0 & 0.0 & 0.0 & 0.6 & 0.0 & 1.5 & 0.3 & 0.0 & 0.2 & 0.2 & 0.1 & 0.4 \\
\hline \multicolumn{15}{|c|}{ Non-fruiting vine } \\
\hline & Leaf & 1 & 0.0 & 0.0 & 0.0 & 0.0 & 0.0 & 0.1 & 0.0 & 0.0 & 0.0 & 0.0 & 0.0 & 0.0 \\
\hline & Stem & 1 & 0.1 & 0.0 & 0.0 & 0.0 & 0.2 & 0.0 & 1.1 & 0.0 & 0.2 & 0.0 & 0.0 & 0.1 \\
\hline & Leaf & 2 & 0.2 & 0.0 & 0.0 & 0.0 & 0.0 & 0.3 & 0.0 & 0.1 & 0.0 & 0.0 & 0.0 & 0.0 \\
\hline & Stem & 2 & 0.3 & 0.1 & 0.1 & 0.0 & 0.0 & 0.0 & 2.6 & 0.2 & 0.7 & 0.0 & 0.0 & 0.3 \\
\hline & Leaf & 3 & 0.3 & 0.0 & 0.0 & 0.0 & 0.0 & 0.1 & 0.0 & 0.6 & 0.0 & 0.0 & 0.0 & 0.0 \\
\hline & Stem & 3 & 0.0 & 0.0 & 0.0 & 0.0 & 0.0 & 0.0 & 1.1 & 0.0 & 0.6 & 0.4 & 0.1 & 0.8 \\
\hline & Leaf & 4 & 0.2 & 0.0 & 0.1 & 0.0 & 0.0 & 0.0 & 0.0 & 0.0 & 0.0 & 0.0 & 0.0 & 0.0 \\
\hline & Stem & 4 & 0.1 & 0.0 & 0.0 & 0.0 & 0.0 & 0.0 & 0.2 & 0.0 & 0.2 & 1.0 & 0.3 & 0.9 \\
\hline Fruit & & & 90.0 & 99.4 & 98.4 & 97.6 & 99.1 & 95.0 & 90.3 & 97.2 & 94.4 & 89.0 & 96.4 & 89.6 \\
\hline Basal sten & & & 0.1 & 0.0 & 0.0 & 0.0 & 0.0 & 0.0 & 0.5 & 0.0 & 0.2 & 0.5 & 0.3 & 0.7 \\
\hline Root & & & 0.0 & 0.0 & 0.0 & 0.1 & 0.0 & 0.0 & 3.2 & 1.5 & 2.5 & 7.2 & 2.6 & 4.9 \\
\hline
\end{tabular}

See the sections and portions of ${ }^{13} \mathrm{CO}_{2}$-fed leaves of the plant in Fig. 9.

${ }^{\mathrm{z}}$ Fruit development stage at ${ }^{13} \mathrm{CO}_{2}$ feeding treatment.

during the fruit developing period. All leaves on the plant were sources of photosynthates translocated to the fruit, whereas photosynthates for roots were mainly translocated from leaves on the non-fruiting vine.

\section{Distribution of ${ }^{13} \mathrm{C}$-photosynthates during fruit development in plants with one vine and fruit respectively}

Plants with a primary vine pinched just above the 30th attached leaf and one fruit set at the 20th leaf were fed ${ }^{13} \mathrm{CO}_{2} .{ }^{13} \mathrm{CO}_{2}$ feeding treatments were performed twice, during middle and late fruit developing stages, on sunny days during the fruit developing period. ${ }^{13} \mathrm{CO}_{2}$ were fed to four different portions, leaves 3 to 5,11 to 13,19 to 21 and 28 to 30 , changing the feeding portion according to the plant (Fig. 10). Once 48 hours had elapsed since the ${ }^{13} \mathrm{CO}_{2}$ feeding treatment, the plants were sampled by respective portions (Fig. 10) and their ${ }^{13} \mathrm{C}$ content was determined.

More than $64.2 \%$ of exported ${ }^{13} \mathrm{C}$ from ${ }^{13} \mathrm{C}$-fed leaves was distributed to the fruit, regardless of the leaf position and fruit developing stage (Table 2). In particular, most of all exported ${ }^{13} \mathrm{C}$ above the 11 th leaves was distributed to fruit, meaning most of the photosynthates in the whole plant were transported to the fruit during the fruit developing period. All leaves on the plant were sources of photosynthates translocated to the fruit, whereas a limited number of lower leaves were sources of photosynthates to roots.

We concluded that fruit weight could be determined by total leaf area, total solar radiation received, and photosynthetic production per plant, because most photosynthates of vertically trained watermelon plants during fruit development were concentrated in the fruit.

\section{Comparison of fruit productivity between vertically and horizontally trained watermelon planting systems}

\section{Comparison of light interception and field photosynthesis of an individual plant}

We compared the relationships between fruit weight and total leaf area per plant, light-reception characteristics, and the field photosynthetic rate between vertically and hor- 


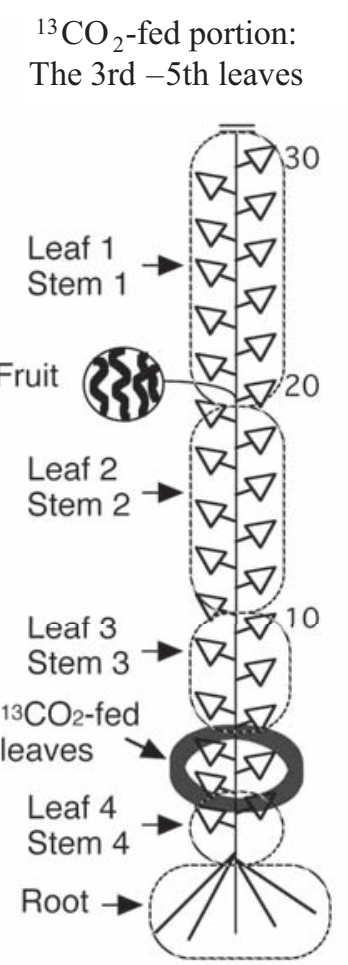

$$
{ }^{13} \mathrm{CO}_{2} \text {-fed portion: }
$$

The 11th -13 th leaves

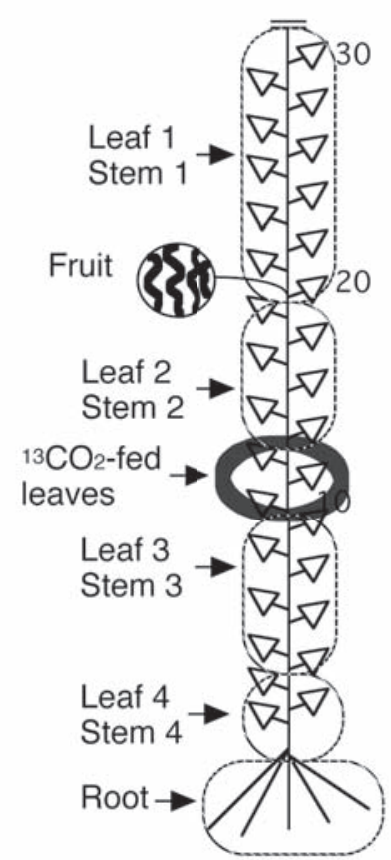

${ }^{13} \mathrm{CO}_{2}$-fed portion:

The 19th -21 st leaves

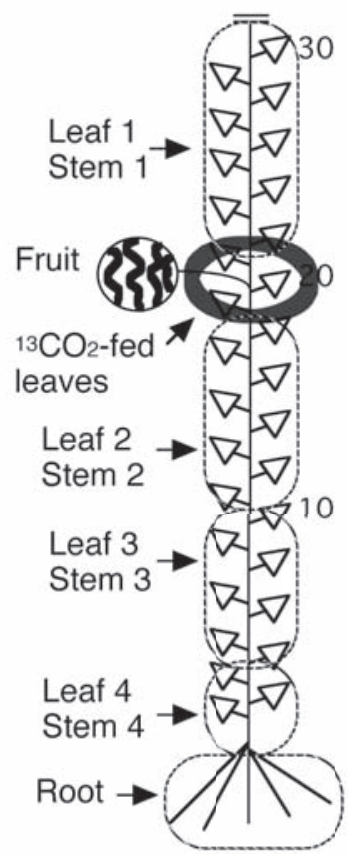

${ }^{13} \mathrm{CO}_{2}$-fed portion: The 28th -30 th leaves

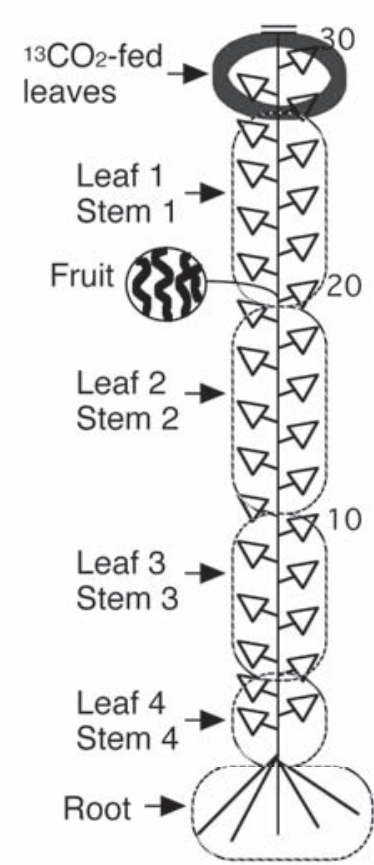

Fig. 10. Portions of ${ }^{13} \mathrm{CO}_{2}$ feeding and sampling sections for analysis in watermelon plants with one vine and fruit respectively

cv. 'Shimaou max RE'. $\bigcirc$ indicate the portions of ${ }^{13} \mathrm{CO}_{2}$ feeding. Sampling sections of leaves and stems were as follows, Leaf 1 and Stem 1 were leaves and stem from the 20th to 30th nodes, Leaf 2 and Stem 2 were leaves and stem from the 11th to 19th nodes, Leaf 3 and Stem 3 were leaves and stem from the 4th to 10 th nodes, and Leaf 4 and Stem 4 were leaves and stem under the 3rd node on the main vine, respectively. ${ }^{13} \mathrm{CO}_{2}$ feeding leaves were excluded from the sampling sections.

Table 2. Distribution percentage of ${ }^{13} \mathrm{C}$ in each section in vertically trained watermelon plants fed ${ }^{13} \mathrm{CO}_{2}$ to leaves on the main vine with one vine and fruit respectively during fruit development

\begin{tabular}{|c|c|c|c|c|c|c|c|c|c|}
\hline \multirow{3}{*}{\multicolumn{2}{|c|}{ Section }} & \multicolumn{8}{|c|}{ Portion of ${ }^{13} \mathrm{CO}_{2}$-fed leaves } \\
\hline & & \multicolumn{2}{|c|}{ 3rd -5th leaves } & \multicolumn{2}{|c|}{ 11th -13th leaves } & \multicolumn{2}{|c|}{ 19th -21th leaves } & \multicolumn{2}{|c|}{ 28th -30th leaves } \\
\hline & & Middle $^{z}$ & Latter $^{2}$ & Middle & Latter & Middle & Latter & Middle & Latter \\
\hline Leaf & 1 & 1.3 & 2.2 & 0.0 & 0.0 & 0.2 & 0.0 & 0.2 & 0.0 \\
\hline Stem & 1 & 0.5 & 0.7 & 0.0 & 0.0 & 0.2 & 0.1 & 1.0 & 2.1 \\
\hline Leaf & 2 & 0.5 & 0.1 & 0.0 & 0.0 & 0.0 & 0.0 & 0.0 & 0.0 \\
\hline Stem & 2 & 1.5 & 5.0 & 0.4 & 2.1 & 0.2 & 0.3 & 0.1 & 0.0 \\
\hline Leaf & 3 & 0.1 & 0.2 & 0.0 & 0.0 & 0.0 & 0.1 & 0.0 & 0.0 \\
\hline Stem & 3 & 3.0 & 2.4 & 0.2 & 0.7 & 0.0 & 0.0 & 0.0 & 0.0 \\
\hline Leaf & 4 & 0.0 & 0.1 & 0.0 & 0.0 & 0.0 & 0.0 & 0.0 & 0.0 \\
\hline Stem & 4 & 2.5 & 5.2 & 0.0 & 0.0 & 0.0 & 0.0 & 0.0 & 0.0 \\
\hline Fruit & & 79.8 & 64.2 & 99.4 & 97.1 & 99.5 & 99.5 & 98.7 & 97.7 \\
\hline Root & & 10.9 & 20.0 & 0.0 & 0.1 & 0.0 & 0.1 & 0.0 & 0.1 \\
\hline
\end{tabular}

See the sections and portions of ${ }^{13} \mathrm{CO}_{2}$-fed leaves of the plant in Fig. 10.

${ }^{\mathrm{z}}$ Fruit development stage at ${ }^{13} \mathrm{CO}_{2}$ feeding treatment. 
izontally trained plants, each with two primary lateral vines

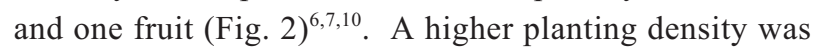
used for vertical training systems, as plants were usually grown more densely under a vertical training system. Solar radiation on individual leaves and the photosynthetic rates of individual leaves were measured as mentioned above.

The fruit weight was significantly lower in vertically trained plants than those horizontally trained, even when the total leaf area was similar (Fig. 11). The solar radiation on, and photosynthetic rates of, the middle and lower leaves of vertically trained plants gradually declined with decreasing leaf position and were lower in vertically trained plants than those horizontally trained (Fig. 12). We concluded that the main reason for the fruit shrinking on vertically trained plants at the respective planting densities was the reduced light received by the middle and lower leaves on vertical plants compared to horizontal ones.

\section{Comparison of fruit productivity at different planting densities}

We compared fruit productivity in vertically and horizontally trained plants with two primary lateral vines and one fruit (Fig. 2) for July- and November-December-harvest crops, respectively ${ }^{10}$. In the July-harvest crop, the planting densities were 95.2, 127.0 and 190.5 plants $\cdot \mathrm{a}^{-1}$ in the vertical training system and 47.6, 63.5 and 95.2 plants $\cdot \mathrm{a}^{-1}$ in the horizontal training system. For the November-December-

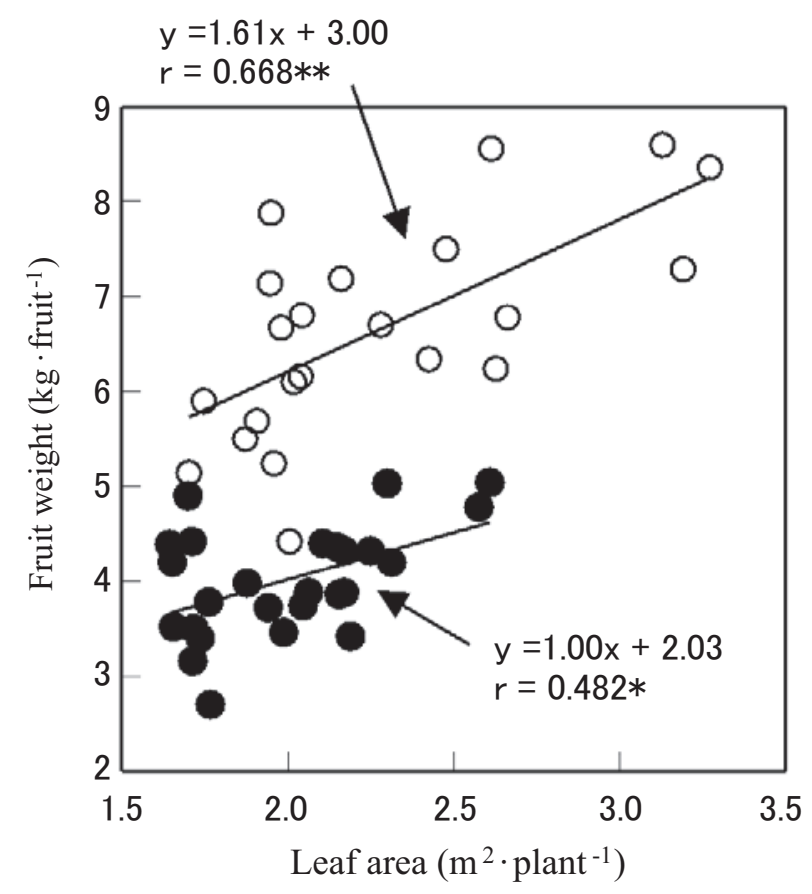

Fig. 11. Relationships between total leaf area per plant and fruit weight in vertically $(\bullet)$ and horizontally $(\circ)$ trained watermelon plants

cv.'Wase Tenryu'. * and ** indicate significance at $P<0.05$ and $P<0.01$, respectively. harvest crop, the planting densities were 47.6, 63.5 and 95.2 plants $\cdot \mathrm{a}^{-1}$ for both training systems. The amount of solar radiation received by individual leaves and the whole plant was estimated as mentioned above.

With increasing planting density, the solar radiation accepted per individual leaf had a tendency to decline in both training systems and for both crops (Fig. 13). This trend intensified for upper leaves in vertically trained plants, but remained relatively constant, regardless of leaf position, in horizontally trained plants. The fruit weight per solar radiation received by plant in vertically trained plants exceeded that in horizontally trained plants during the Julyharvest, and resembled that in the November-Decemberharvest (Fig. 14). Although the fruit weight decreased in vertical and horizontal training systems with increasing planting density, the degree of decrease in fruit weight in vertical training systems was smaller than in horizontal ones, meaning the fruit weight in vertical systems exceeded that in horizontal systems under higher planting densities (Fig. 15). As the planting density increased, the fruit yield per unit land area with vertical training systems increased and exceeded that of horizontal training systems.

\section{Advantage of vertical training systems for watermelons and prospects for further research}

Based on the results obtained, certain advantages of

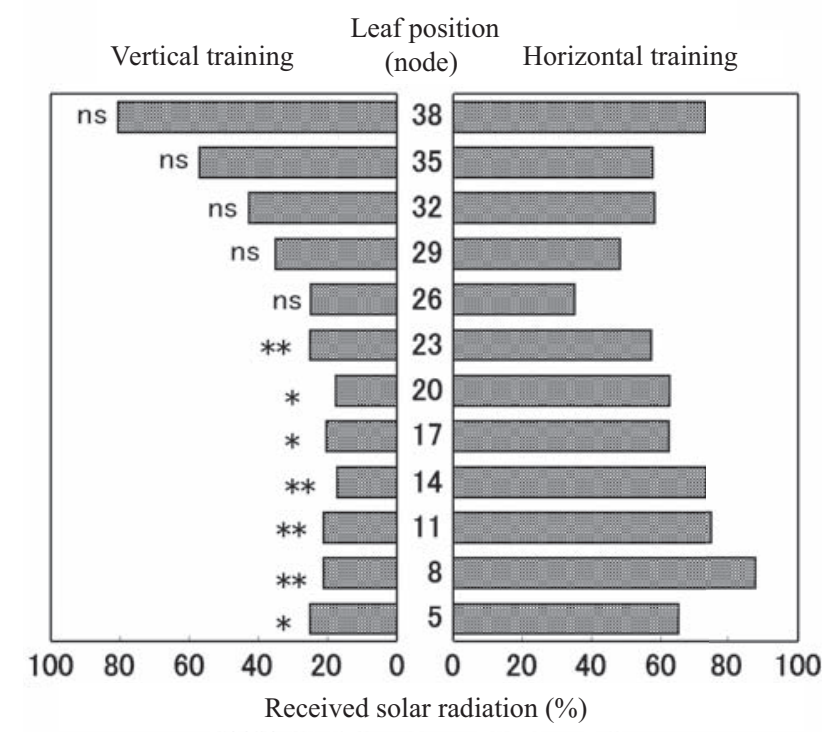

Fig. 12. Profile of the solar radiation on individual leaves of vertically (left) and horizontally (right) trained watermelon plants during fruit development

cv. 'Wase Tenryu'. Values of received solar radiation on individual leaves were represented by the percentage to integrated solar radiation above the plant canopy. $*$, ** indicate significant differences at $P<0.05$ and $P<0.01$, respectively, by $t$-test when comparing of vertically trained plants $(n=14-15)$ and horizontally trained plants $(\mathrm{n}=5)$. 


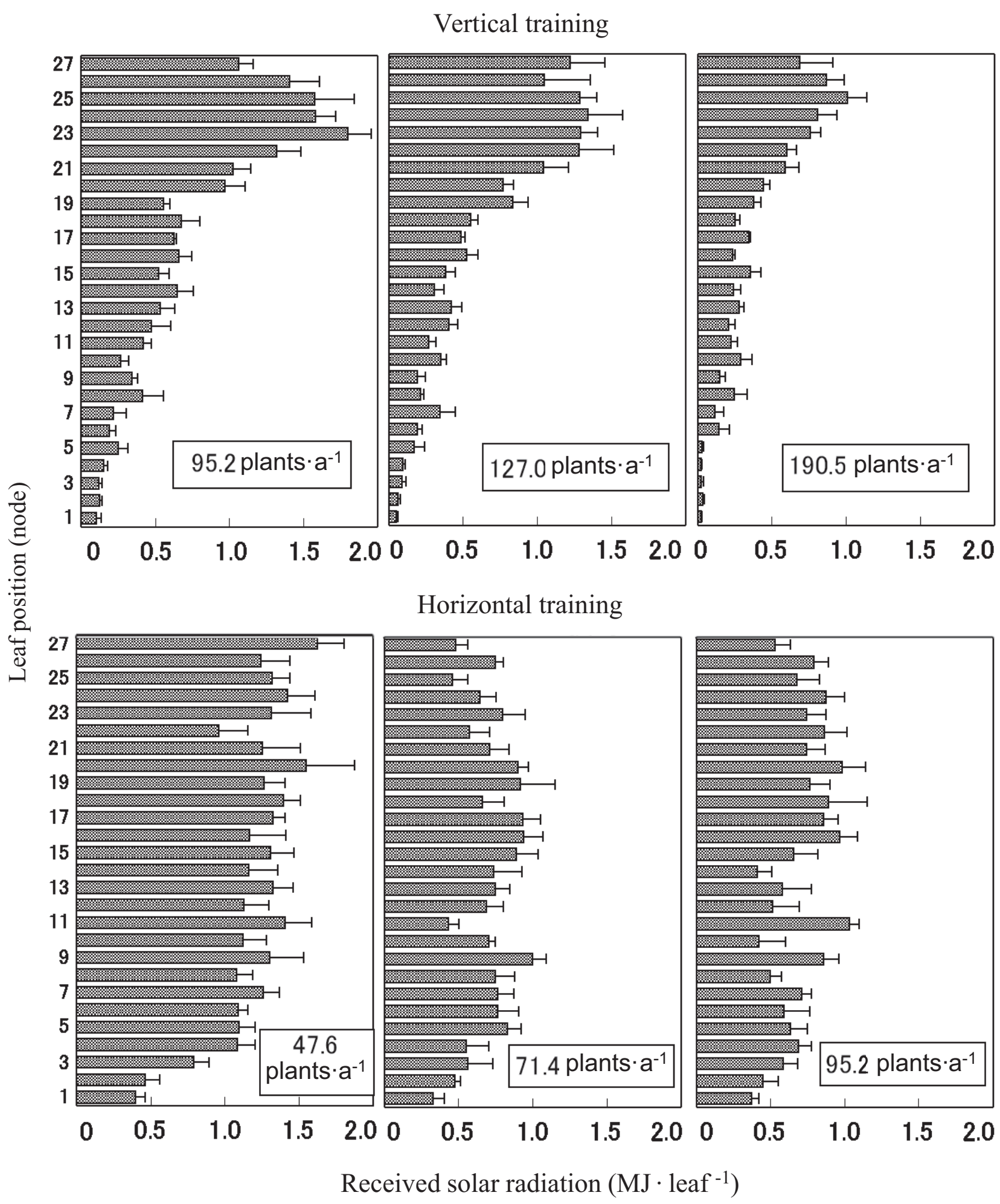

Fig. 13. Profile of the solar radiation received for individual leaves of vertically (upper) and horizontally (lower) trained watermelon plants during fruit development at various planting densities in the July-harvest crop

cv. 'Shimaou max RE'. Values of the solar radiation received for individual leaves were estimated by multiplying the solar radiation received by the solarimeter film on the leaf by the individual leaf area. Horizontal bars indicate SE $(n=5)$. 


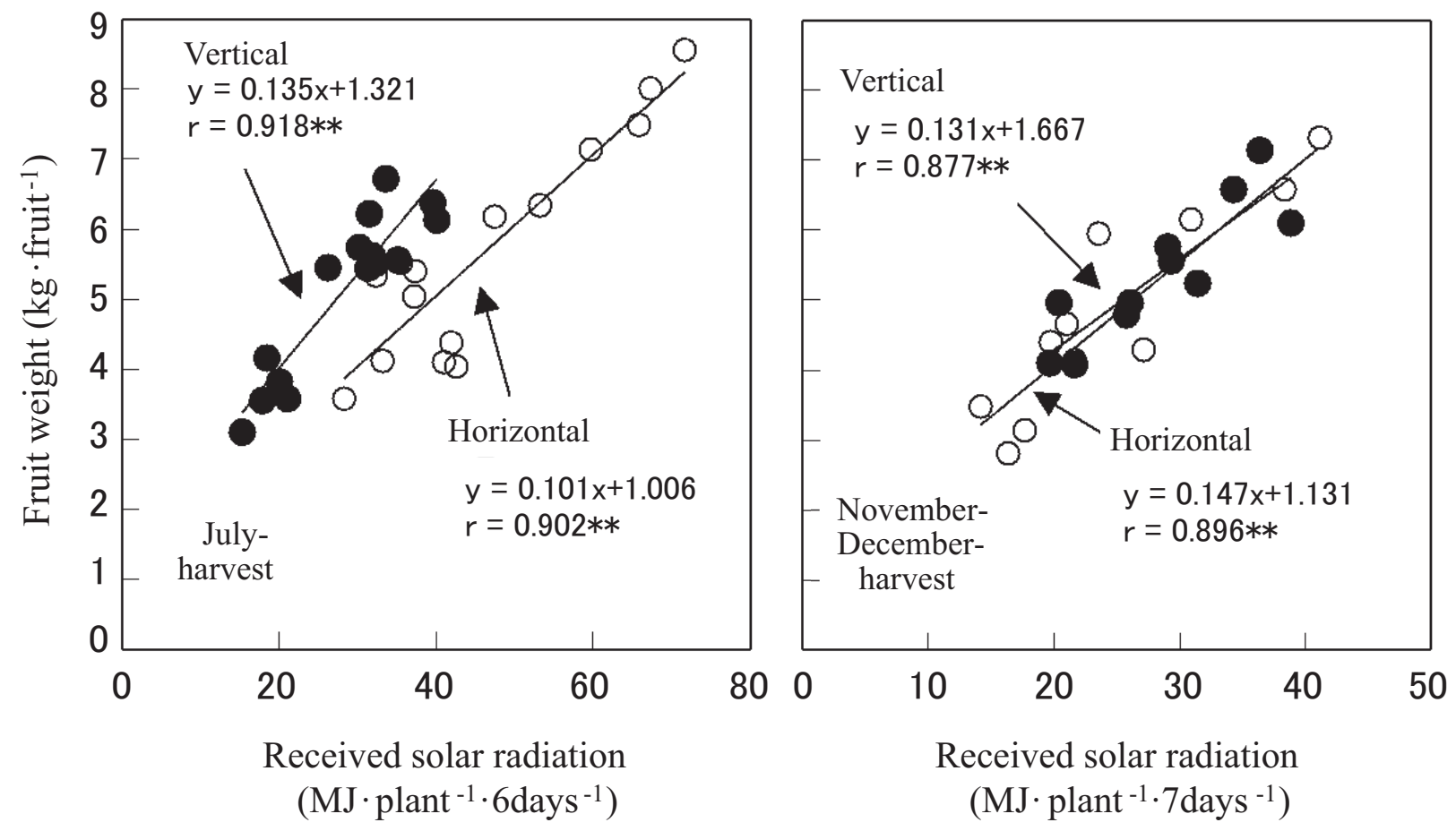

Fig. 14. Relationships between the solar radiation received by the whole plant and fruit weight during the fruit development of vertically and horizontally trained watermelon plants in the July- and November-December-harvest crops cv. 'Shimaou max RE'. ** indicates significance at $P<0.01$.

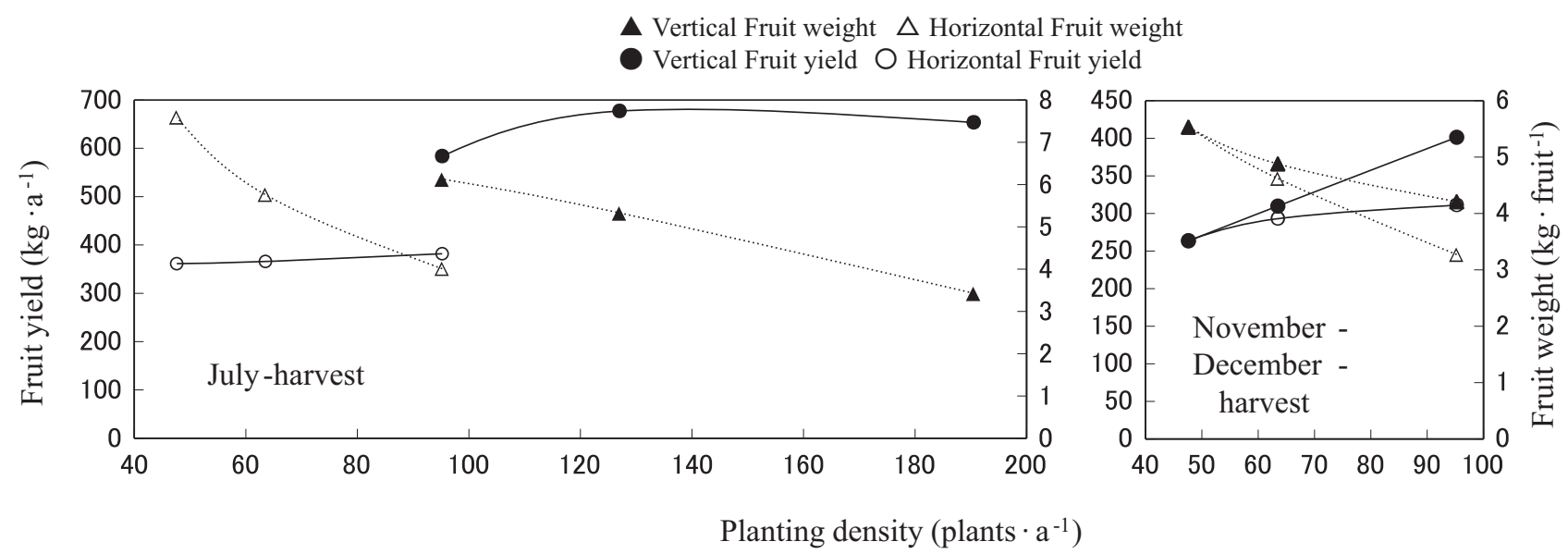

Fig. 15. Effect of planting density on individual fruit weight and fruit yield in vertical and horizontal training systems in the July- and November-December- harvest crops respectively (left and right) cv. 'Shimaou max RE'.

vertical training systems over conventional, horizontal training systems were objectively confirmed. Vertical training of watermelon plants increased the fruit yield per unit land area under a higher planting density than horizontal training, with no loss of light-use efficiency. Vertical training systems benefit efforts to meet recent marketing trends for small and high-quality fruit and have the potential to increase areas of production in Japan, especially for inten- sively protected cultivation.

The finding that total leaf area or total solar radiation received per plant were closely related to fruit weight in respective systems, vertical and horizontal training, suggested that fruit weight or fruit yield per unit land area, or both, could be predicted from estimated solar radiation. It also suggested that fruit weight could be controlled by adjusting the planting density or leaf area per plant, or both. 
We also found that the solar radiation received per plant was likely to be a more useful index than leaf area per plant for estimating fruit production with different training systems, especially when light-interception characteristics differed widely (e.g. between the vertical and horizontal training systems studied here). Using solar radiation received per plant as a benchmark should help when developing productive training systems for fruit vegetables in the field.

\section{References}

1. Ministry of Agriculture, Forestry and Fisheries, Japan : The 87th statistical yearbook (2011 - 2012). http://www.maff.go. jp/e/tokei/kikaku/nenji_e/87nenji/index.html

2. Nanba, H. \& Matsumoto, T. (1975) Effects of few training method, number of bearing on yield and quality in housemelon. Kinki chugoku nogyo kenkyu (Kinki Chugoku Agric. Res.), 50, 48-50 [In Japanese].

3. Oishi, T. et al. (2010) Comparison of crop yield and working posture between hedge-row and spread over the ground trained in wax gourd (Benincasa hispida (Thunb.) Cogn) plants. Okinawa ken nougyo kenkyu senta kenkyu hokoku (Bull. Okinawa Pref. Agric. Res. Cent.), 4, 32-35 [In Japanese with English summary].

4. Ohki, H. \& Sakiyama, H. (1995) Studies on the retarding cultivation of squash (Cucubita maxima DUCH.) harvested in December under non-heated plastic greenhouse. Chiba ken nougyo shikenjyo kenkyu houkoku (Bull. Chiba Agric. Exp. Stn.), 36, 47-55[In Japanese with English summary].

5. Watanabe, S. et al. (2001a) Simple measurement of lightinterception by individual leaves in fruit vegetables by using an integrated solarimeter film. Seibutsu kankyo chosetsu (Environ. Control in Biol.), 39, 121-125[In Japanese with English summary].

6. Watanabe, S. et al. (2001b) Comparison of light interception and field photosynthesis between vertically and horizontally trained watermelon [Citrullus lanatus (Thunb.) Matsum. et Nakai] plants. J. Japan. Soc. Hort. Sci., 70, 669-674.

7. Watanabe, S. et al. (2001c) Relationships between total leaf area and fruit weight in vertically and horizontally trained watermelon [Citrullus lanatus (Thunb.) Matsum. et Nakai] plants. Engei gakkai zassi (J. Japan. Soc. Hort. Sci.), 70, 725-732 [In Japanese with English summary].

8. Watanabe, S. et al. (2003a) Effects of node order of fruit set on total leaf area and fruit weight of vertically trained watermelon [Citrullus lanatus (Thunb.) Matsum. et Nakai] plants. Engeigaku kennkyu (Hort. Res. (Japan)), 2, 35-38 [In Japanese with English summary].

9. Watanabe, S. et al. (2003b) Effect of planting density of fruit size, light-interception and photosynthetic activity of vertically trained watermelon (Citrullus lanatus (Thunb.) Matsum. et Nakai) plants. J. Japan. Soc. Hort. Sci., 72, 497-503.

10. Watanabe, S. (2013) Fruit productivity of vertically trained watermelon [Citrullus lanatus (Thunb.) Matsum. et Nakai] Yasai chagyo kenkyuusho kenkyu houkoku (Bull. Natl. Inst. Veg. \& Tea Sci.), 12, 7-60 [In Japanese with English summary]. 